\title{
A presumptive new variant of Norrie's disease
}

\author{
C. A. MOREIRA-FILHO AND I. NEUSTEIN
}

From Laboratório de Genética Humana, Departamento de Biologia, Universidade de São Paulo, São Paulo; and Departamento de Oftalmologia e Otorrinolaringologia da Escola Paulista de Medicina, São Paulo, Brazil

SUMmARY The present report describes a Brazilian Negro sibship with six males affected by a presumptive new variant of Norrie's disease, an X-linked congenital oculo-acoustical-cerebral degeneration. In addition to the typical stigmata of the disease, all the patients were microcephalic and two of them had cryptorchidism. Possible non-genetic aetiology was investigated with negative results. Xg blood group studies were informative and the lod scores are given, together with those for two previously reported families with Norrie's disease.

Norrie's disease is a sex-linked recessive disorder causing retinal degeneration. Mental retardation appears in one-third of the cases and sensory hearing loss is present with equal frequency. The onset of bilateral blindness occurs at birth or during the first few months of life. The gene has complete penetrance, but its expressivity is highly variable, especially with respect to mental retardation and hearing loss (Warburg, 1971, 1975). Genetic linkage data (Warburg et al., 1965; Nance et al., 1969) are compatible with loose linkage between the loci of Norrie's disease $(N d)$ and glucose-6-phosphate Received for publication 12 August 1978 dehydrogenase deficiency $(G 6 P D)$, but no measurable linkage between $X g$ and $N d$ loci. The family presented here is the only one to date where microcephaly, cryptorchidism, and measurable Xg linkage are associated with the classical signs of Norrie's disease. These are also the first cases of Norrie's disease reported in South America.

\section{Subjects and methods}

The patients belonged to a Brazilian Negro family. All the affected individuals were male and belonged to the same sibship (Fig. 1), their ages varying from

I

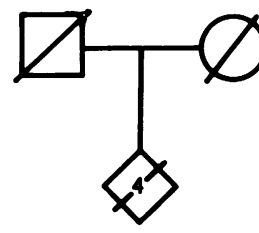

II
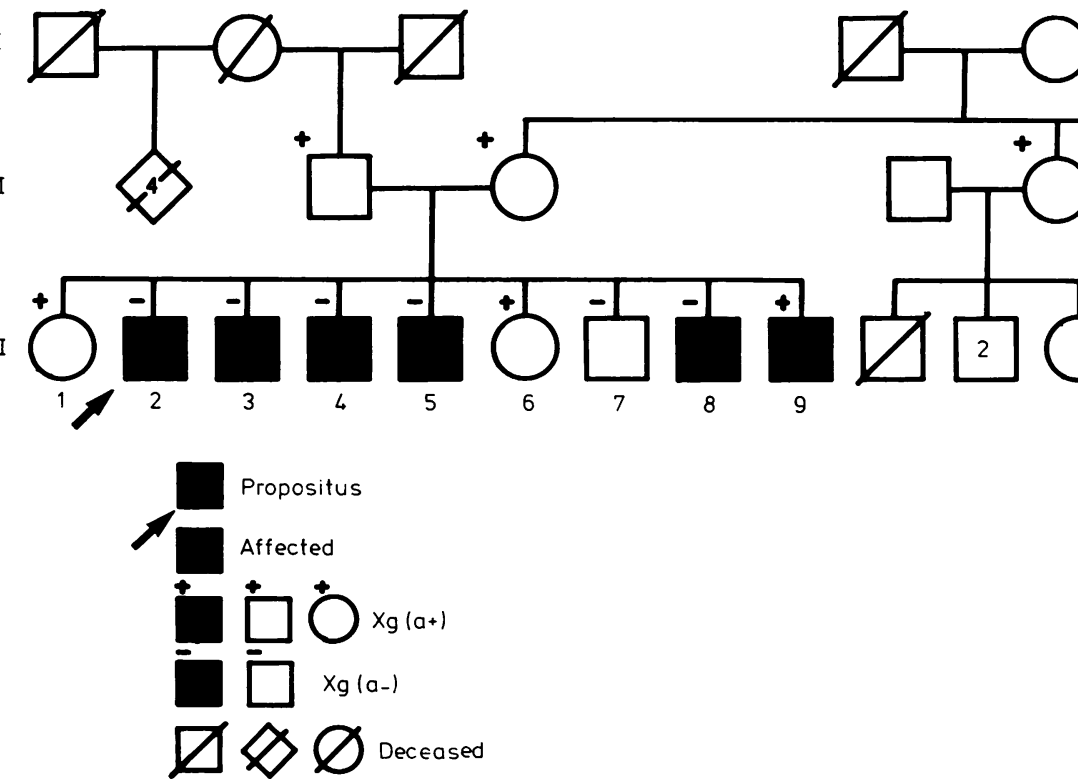

Fig. 1 Pedigree of family. 
3 to 15 years. The parents (non-consanguineous) and their children were submitted to clinical examination, including ophthalmological and otological studies. Two affected boys, who could not respond to audiometric tests because of poor mental condition, were submitted to electrocochleography. Cephalic circumferences were measured and compared with the normal means for the patient's age.

In order to check the non-genetic factors causing microcephaly or blindness, $x$-ray examination of the skull, IgM fluorescent antibody tests for toxoplasmosis, and a search for cytomegalovirus intranuclear inclusion bodies were performed. Levels of serum testosterone were measured by radioimmunoassay in two of the affected boys (III. 4 and III.5), since these patients showed clinical signs of hypogonadism.

Psychological tests (WISC and Ghwaki-Kohs Tactile Block Design) were used for evaluating the intellectual level of the patients.

Linkage of the $N d$ locus with $G 6 P D$ and $X g$ loci was investigated. The study of G6PD was made by spectrophotometric assay (Saldanha et al., 1969). Xg blood groups were determined in London by $\mathrm{Dr}$ Ruth Sanger and the staff of the MRC Blood Group Unit.

\section{Case reports}

The clinical diagnosis of Norrie's disease was based on severe ocular affection, mental retardation, and hearing loss. X-linked congenital retinoschisis and $\mathrm{X}$-linked microphthalmia associated with mental retardation were excluded. Laboratory tests for congenital toxoplasmosis and cytomegalovirus infections were negative. $X$-ray examination of the skull revealed diminished cranial diameters and failed to show intracranial calcifications. These data enabled us to discard non-genetic aetiological factors.

Ophthalmological findings, summarised in Table 1 , show various grades of ocular morphology disorganisation. The descriptions refer to the more affected eye, but the differences between right $\stackrel{\mathrm{P}_{\text {Q }}}{\mathrm{a}}$ left eyes were small in all the cases. The lesst affected patient (III.5) could perceive light, hid clear cornea and lens, and normal anterior vitreogs.

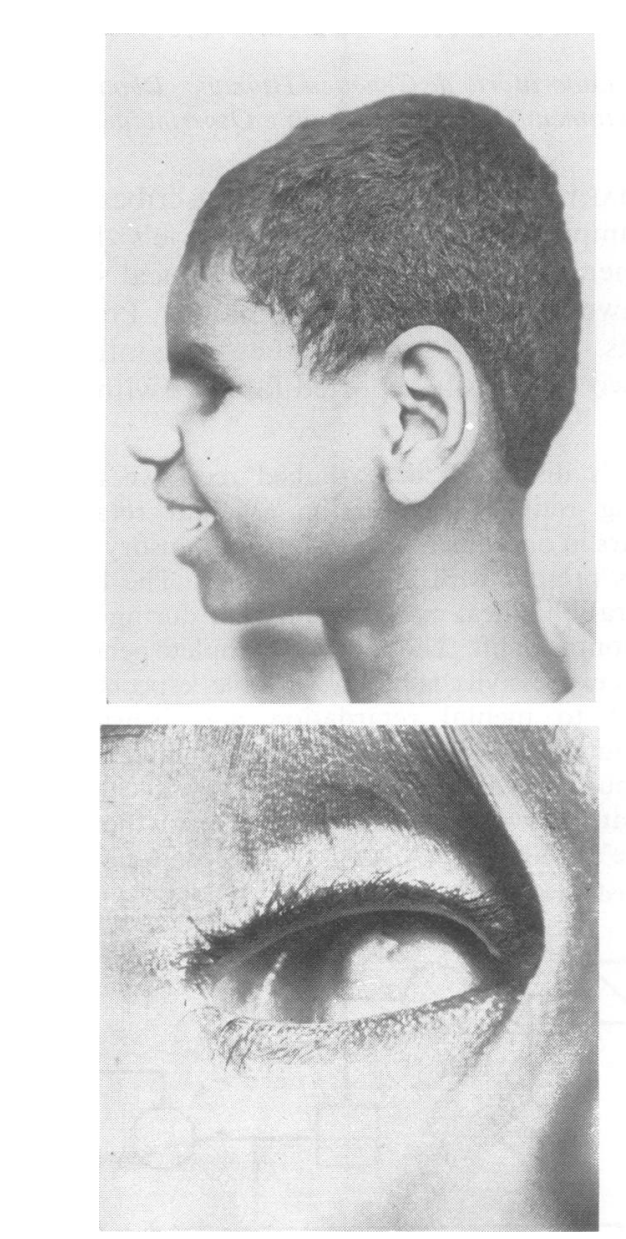

Fig. 2 Patient III.2. The photographs show typical phthisis bulbi and microcephaly.

Table 1 Ophthalmological findings

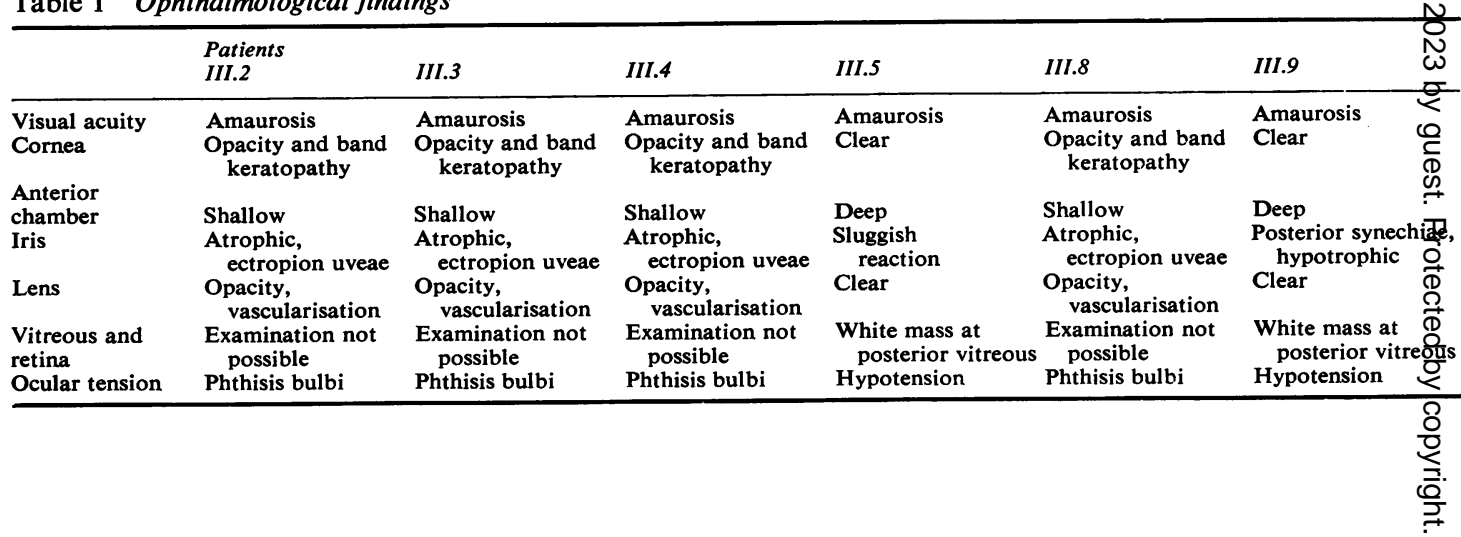


The posterior vitreous was invaded by a vascularised mass which made the retina inaccessible to examination. Intraocular tension was $5 \mathrm{mmHg}$. The most severely affected patient (III.2, Fig. 2) presented severe ocular morphology disorganisation, amaurosis, ocular atrophy, band keratopathy, atrophy of the iris, shallow anterior chamber, deep-set eyes, and presence of intraocular calcifications (shown by $x$-ray examination).

On clinical examination microcephaly was found in all the patients (Table 2). Bilateral cryptorchidism with a palpable inguinal testis was present in cases III.4 and III.5. Pubic and axillary hair was completely absent in these patients. Serum testosterone levels were $42.9 \mathrm{ng} / 100 \mathrm{ml}(1.49 \mathrm{nmol} / \mathrm{l})$ in case III. 4 and $45.8 \mathrm{ng} / 100 \mathrm{ml}(1.59 \mathrm{nmol} / \mathrm{l})$ in case III.5, both values being below normal for the patient's age (Tanner, 1975).

Audiometric tests revealed normal hearing thresholds for cases III.2, 3, 5, and 9. Electrocochleography was performed in cases III.4 and III.8. Lesions in the cochlea, at the external cilliary cells, resulting in severe hearing impairment were found in case III.4. A peripheral disorder of the auditory organ, causing complete hearing loss, was detected in case III.8.

The psychological tests performed in cases III.2 and III.3 revealed IQs of 45 and 65 , respectively. Case III. 9 was not old enough to be tested and the other patients (III.4, 5, and 8) were obviously mentally retarded.

Table 2 Head circumferences of patients

\begin{tabular}{lll}
\hline Patient & Age $(y$ and $m)$ & $\begin{array}{l}\text { Head circumference* } \\
(\mathrm{cm})\end{array}$ \\
\hline III.2 & $15 \cdot 6$ & $61 \cdot 3$ \\
III.3 & $14 \cdot 3$ & $50 \cdot 9$ \\
III.4 & $13 \cdot 2$ & $48 \cdot 5$ \\
III.5 & $12 \cdot 1$ & $46 \cdot 9$ \\
III.8 & $5 \cdot 2$ & $44 \cdot 3$ \\
III.9 & 3.4 & $45 \cdot 3$ \\
\hline
\end{tabular}

*, all values more than 2 SD below the normal mean for age (according to data from Nellhaus, 1968).

\section{Linkage analysis}

Only the genes for $\mathrm{Xg}$ blood group factor and Norrie's disease were segregating informatively (no G6PD variant or deficiency was identified). The data were analysed by the application of the lod scores of Morton (1955) as presented in the tables of MaynardSmith et al. (1961). The lod scores are given in Table 3, together with the antilogs of their sums, which represent the relative probabilities of the recombination fraction $\theta$. We also pooled our results with the previous data of Warburg et al. (1965) and Nance et al. (1969).

\section{Discussion}

The pedigree data favour the $\mathrm{X}$-linked recessive mode of inheritance, since only males are affected. The probability of chance occurrence under the hypothesis of autosomal recessive inheritance is only 1/64. Moreover, all the clinical signs described for the classical form of Norrie's disease, which undoubtedly depends on an X-linked gene, are present in our cases: mental retardation, hearing loss, and typical ophthalmological stigmata.

Hara et al. (1969) found hypogonadism in a Negro kindred with Norrie's disease. Of the 6 patients in our pedigree, 2 had both clinical and hormonal features of hypogonadism. It is, therefore, probable that such findings are non-obligatory components of the disease, though this is not mentioned in any of the families reviewed by Warburg (1975).

Microcephaly is described here for the first time in association with Norrie's disease. Its presence in the 6 patients suggests that we are dealing with a new variant of Norrie's disease. In order to establish this, it is recommended that a search for microcephaly be made both in new and in already reported cases of Norrie's disease.

The genetical relationship between the two forms of Norrie's disease could result from the following situations: (1) the two forms depend on different

Table 3 Lod scores for Norrie's disease and Xg

\begin{tabular}{|c|c|c|c|c|c|c|c|c|c|}
\hline & \multicolumn{9}{|c|}{ Recombination fraction $(\theta)$} \\
\hline & 0.05 & $0 \cdot 1$ & 0.15 & 0.2 & 0.25 & $0 \cdot 3$ & 0.35 & 0.4 & 0.45 \\
\hline $\begin{array}{r}\text { Present study } \\
z_{i} 5: 2 e_{1} 6: 1 \\
\text { Warburg et al. }\end{array}$ & $-0 \cdot 902$ & -0.414 & $-0 \cdot 183$ & -0.062 & -0.001 & 0.023 & 0.025 & 0.015 & 0.004 \\
\hline $\begin{array}{l}(1965) \\
\text { Nance et al. }\end{array}$ & $-3 \cdot 691$ & $-2 \cdot 324$ & $-1 \cdot 557$ & -1.069 & -0.722 & -0.467 & -0.281 & -0.146 & -0.056 \\
\hline $\begin{array}{l}\text { (1969) } \\
\text { Total sum of lod }\end{array}$ & $-4 \cdot 465$ & $-2 \cdot 789$ & $-1 \cdot 870$ & $-1 \cdot 267$ & $-0 \cdot 841$ & -0.532 & $-0 \cdot 308$ & -0.151 & -0.050 \\
\hline $\begin{array}{l}\text { scores } \\
\text { Relative probability }\end{array}$ & $t^{-9.058}$ & $-5 \cdot 527$ & $-3 \cdot 610$ & $-2 \cdot 398$ & $-1 \cdot 564$ & -0.976 & -0.564 & -0.282 & $-0 \cdot 102$ \\
\hline $\begin{array}{l}\text { for our data } \\
\text { Relative probability }\end{array}$ & ty $0 \cdot 125$ & $0 \cdot 385$ & 0.656 & 0.867 & 0.998 & $1 \cdot 054$ & 1.059 & $1 \cdot c 35$ & 1.009 \\
\hline for pooled data & 0.000 & 0.000 & 0.000 & 0.004 & 0.027 & $0 \cdot 106$ & 0.273 & 0.522 & 0.791 \\
\hline
\end{tabular}


alleles; (2) they depend on different loci on the $\mathrm{X}$-chromosome; (3) they result from the action of a modifier on the $\mathrm{Nd}$ gene.

If it could be shown that the genes causing the two forms of the disease are located at different distances from an X-linked marker, then they could be assigned to different loci. Only more linkage data in familial cases of Norrie's disease with associated microcephaly will show whether two loci are involved.

The collaboration of the following people is gratefully acknowledged: Dr Norma C. Magnelli, who referred the cases; Dr Mayana Zatz and Dr $O$. Frota-Pessoa for a critical review of the manuscript; Dr Ruth Sanger for $\mathrm{Xg}$ blood group typing and for reading the manuscript; Dr Sueli B. Itskan for G6PD determinations; and Drs Yotaka Fukuda, Samuel Reibsheid, Nilde Gerbelli, P. A. Otto, and Mr Fabio Levi for their assistance.

This work was supported by a grant from Fundação de Amparo à Pesquisa do Estado de São Paulo (FAPESP).

\section{References}

Hara, S., Hansen, A., Crump, P., Elliott, J., and Nance, W. (1969). Clinical studies of a Negro family with Norrie's disease. Quoted as in preparation by Nance et al. (1969).

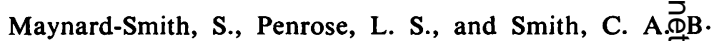
(1961). Mathematical Tables for Research Workers; in Human Genetics. Churchill, London.

Morton, N. E. (1955). Sequential tests for the detection of linkage. American Journal of Human Genetics, 7, 227- 8.

Nance, W. E., Hara, S., Hansen, A., Elliott, J., Lewis, and Chown, B. (1969). Genetic linkage studies in a Nergro kindred with Norrie's disease. American Journal of Human Genetics, 21, 423-429.

Nellhaus, G. (1968). Composite international and interrof graphs. Pediatrics, 41, 106-114.

Saldanha, P. H., Nóbrega, F. G., and Maia, J. C. C. (19ब9). Distribution and heredity of erythrocyte G6PD actintty and electrophoretic variants among different racial groups at São Paulo, Brazil. Journal of Medical Genetics,6, 48-54.

Tanner, J. M. (1975). Growth and endocrinology of The $_{\text {the }}$ adolescent. In Endocrine and Genetic Diseases of Childh $\vec{\theta} \rho d$ and Adolescence, pp. 14-64. Ed. by L. Gardner. Saunders, Philadelphia.

Warburg, M. (1971). Norrie's Disease. Birth Defeç Original Article Series, Vol. VII, No. 3, 117-124.

Warburg, M. (1975). Norrie's disease: differential diagnosis and treatment. Acta Ophthalmologica, 53, 217-236.

Warburg, M., Hauge, M., and Sanger, R. (1965). Norzte's disease and the $\mathrm{Xg}$ blood group system: linkage data. P:ta Genetica et Statistica Medica, 15, 103-115.

Requests for reprints to Dr C. A. Moreira-Fillio, Departamento de Biologia, Instituto de BiociêncFlgs, Universidade de São Paulo, Caixa Postal 11461, São Paulo 01000, SP, Brazil. 